\title{
Bifidobacterium dentium
}

National Cancer Institute

\section{Source}

National Cancer Institute. Bifidobacterium dentium. NCI Thesaurus. Code C86198.

A species of anaerobic, Gram-positive, rod shaped bacteria assigned to the phylum

Actinobacteria. This species nonmotile, non-spore forming, catalase and indole negative, does not reduce nitrate and ferments arabinose, xylose, ribose, gluconate, cellobiose, lactose, mannitol, melezitose, salicin, and starch. B. dentium is an opportunistic pathogen associated with tooth decay. 